\title{
Towards an adapted ovalization system for flexible airfield pavement interface characterization using rolling-wheel or HWD loads
}

\author{
Maissa Gharbi $^{1 *}$, Michael Broutin ${ }^{1}$, Thomas Schneider ${ }^{1}$, Maindroult \\ Stephane $^{1}$ \\ ${ }^{1}$ French Civil Aviation Technical Center (STAC), Bonneuil-sur-Marne, France \\ *maissa.gharbi@regis-dgac.net
}

\author{
Armelle Chabot ${ }^{2}$ \\ ${ }^{2}$ MAST-LAMES, Univ Gustave Eiffel, IFSTTAR, F-44344 Bouguenais, France
}

\begin{abstract}
Monitoring pavement condition during its service life is paramount in order to anticipate and optimize the potential maintenance work. For this purpose, different non-destructive techniques (NDT) are used to evaluate the pavement distresses condition and to provide necessary information for the maintenance tasks, but they do not enable, on their own, a reliable assessment of the interface conditions. The ovalization test developed in the 70s by the CEREMA (Centre d'étude et d'expertise sur les risques, l'environnement, la mobilité et l'aménagement) is an interesting method to evaluate the interface bonding condition between pavements layers. It measures the core diameter variation at different depth levels and simultaneity in three horizontal directions (longitudinal (L), transverse $(\mathrm{T})$ and $45^{\circ}$ related to the loading direction) over the cross of a rolling wheel loads. The existing ovalization equipment needs to be adapted to test the flexible airfield pavement under rolling and HWD loads. This paper presents two new prototypes for the ovalization device. They are characterized by the simultaneous use of displacement sensors positioned in the three identified horizontal directions previously mentioned and at several depths within the bituminous layer. The first tests performed with this new system under rolling wheel loads, pseudo-static plate loads and HWD dynamic impulse loads at the STAC's full-scale airfield pavement test facility in Bonneuil (France) are presented. Experimental results are analyzed and compared to 3D finite element simulations.
\end{abstract}

Keywords Ovalization test, Flexible airfield pavement, Interfaces, Modeling.

This is a pre-print of a contribution published in Accelerated Pavement Testing to Transport Infrastructure Innovation - Proceedings of the 6th APT Conference. In: Chabot A., Hornych P., Harvey J., Loria-Salazar L. (eds) Accelerated Pavement Testing to Transport Infrastructure Innovation, Lecture Notes for Civil Engineering, vol. 96: 389-398. Springer, Cham.

The final authenticated version is available online at: https://oi.org/10.1007/978-3030-55236-7_53 


\section{Introduction}

The mechanical behavior of the interfaces between bituminous layers is a crucial parameter for the pavement design method (Corte and Goux 1996; Gharbi 2018). The debonding phenomena of those interfaces reduce actually drastically the durability of flexible pavements. Pavement diagnosis, including the evaluation of interface conditions, is therefore a crucial step in order to evaluate their residual life, to anticipate potential maintenance work and to avoid the apparition of early distress in the airfield pavement. There are a few in-situ tests which allow the evaluation of the interface condition between bituminous layers (Petit et al. 2018). Nondestructive techniques have appeared for the last decades to this end, but still present some limitations to provide, on their own, reliable information about interfaces condition (Sadoun et al., 2016; Broutin et al., 2019). Developed in the 70s, a first ovalization test was proposed to evaluate interface bond condition between pavement layers ( Kobisch and Peyronne, 1979; Goacolou et al., 1983; Martin and Benaben, 1995). It leads to identify the horizontal strain of a cavity at different depth levels and in three horizontal directions ( $\mathrm{L}, \mathrm{T}$ and $45^{\circ}$ ) under rolling wheel loads. Indeed, the stresses and strains inside the multi-layered structure are estimated from the variation of the cavity diameter in those three directions. Due to its delicate implementation this test was little used since its development.

Recently, the first ovalization system was upgraded by the CEREMA (Ruiz and Voisin 2019) into the second generation tridirectional probe for the simultaneous measurement of the core variation in the three plane directions.

This second generation system was tested (Gharbi et al. 2020) under the Heavy Weight Deflectometer (HWD) impulse loading at the STAC full-scale airfield pavement test facility built on the CER site (Rouen, France). Some limitations were highlighted, such as the insufficient acquisition frequency, the impossibility to make simultaneous multi-height measurements and to position HWD plate test centered above the cavity.

In that recent work, it was shown that the existing ovalization equipment needs to be modernized and adapted to the flexible airfield pavement under HWD loads.

The mains objective is to enable the measurement of the cavity diameter variation under both rolling loading and the Heavy Weight Deflectometer (HWD) impulse loading (Figure 1), which implies:

- a specific acquisition rate, at least $300 \mathrm{~Hz}$,

- simultaneous multi-height measurements at four depth levels within the bituminous course layer: 1- at the surface; 2 - above the BBA/GB interface; 3- below the BBA/GB interface and 4- at the bottom of the bituminous layer,

- the possibility to measure the cavity diameter variation under HWD loads involving a loading plate positioned at different distances from the cavity, including a centered position above the cavity (see Figure 4). 


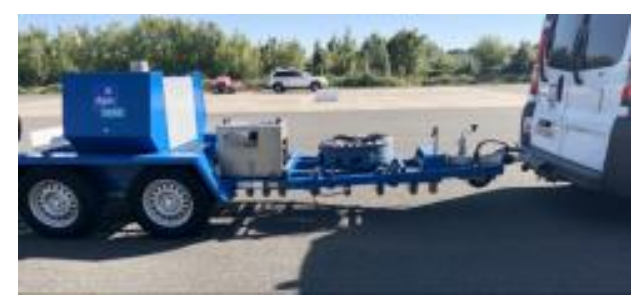

Fig. 1 STAC HWD (Dynatest)

The STAC launched then a R\&D project to develop a new system, which enables overcoming the aforementioned limitations.

Furthermore, the analysis method needs to be modernized.

This paper describes firstly new prototypes of the ovalization device proposed. Secondly, results from measurements under the (HWD) impulse loading at the STAC full-scale airfield pavement test facility are presented. Thirdly an elastic dynamical 3D FE modeling is proposed, and the first numerical results obtained are described. The FE simulation results are finally illustrated and compared to experimental results.

\section{Description of The Two New Ovalization Devices}

The new ovalization systems involve, in their initial version presented here, six DD1 displacement sensors. Two simple designs are proposed with the six sensors positioned in pairs for each direction in order to measure the diameter variation of the cavity in three directions in the horizontal plane $\left(\mathrm{L}, \mathrm{T}, 45^{\circ}\right)$. Both prototypes are designed for a cavity diameter of $162 \mathrm{~mm}$. The measurement range of the sensors is $\pm 2,5 \mathrm{~mm}$ with an uncertainty below $0.5 \%$. Sensors are connected to an acquisition system, QuantumX model (HBM), which allows performing measurements with an adequate frequency for the HWD impulse loading. The comparison of the two prototypes is thereafter presented.

\subsection{Prototype 1}

The first prototype consists of a self-supporting system in which sensors are indirectly placed in contact with the different sides of the cavity. Each sensor is vertically set up through an aluminum blade whose end is connected to an aluminum rod equipped with a tip in contact with the cavity inner wall. Springs are used to ensure contact between tips and cavity walls. They lean against a central octagonal plastic piece (see Figure 2) and are chosen stiff enough to secure the system stabil- 
ity but flexible enough to ease setting up. The Figure 2 a shows the $3 \mathrm{D}$ modelling of the first prototype manufactured with a $3 \mathrm{D}$ printer and the CAD SolidWorks software.

(a)

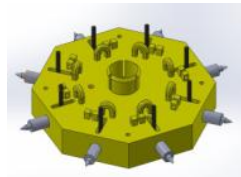

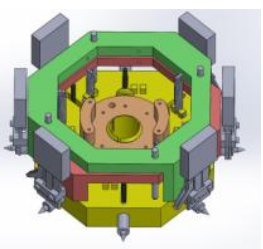

(b)

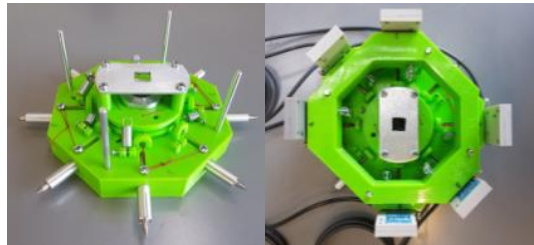

Fig. 2 First Ovalization prototype: a) SolidWorks design, b) manufactured prototype using a 3D printer

\subsection{Prototype 2}

The second prototype contains six sensors positioned two per horizontal directions on an octagonal piece fixed to a central rod (Figure 3a). The latter is placed on a circular base via a vertical spring. The use of a vertical spring aims to limit the influence of subbase vertical displacements and associated vertical vibrations. Two horizontal and stiff springs are used in order to ensure the horizontal stability of the octagonal piece in the cavity. The springs are chosen stiff enough in order to limit possible horizontal vibration due to the HWD dynamic loading. Sensors are directly set in contact with the cavity inner walls with the help of a screw fixed to the tip of each sensor. The Figure 3 a shows the $3 \mathrm{~d}$ modelling of the second prototype carried out with the CAD SolidWorks software.

(a)

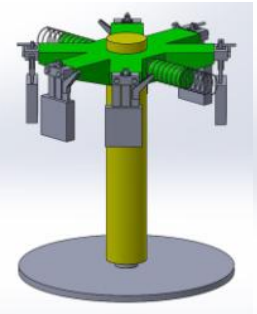

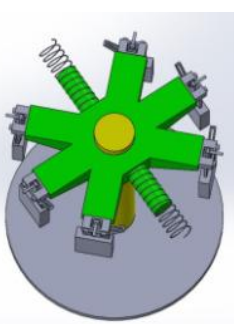

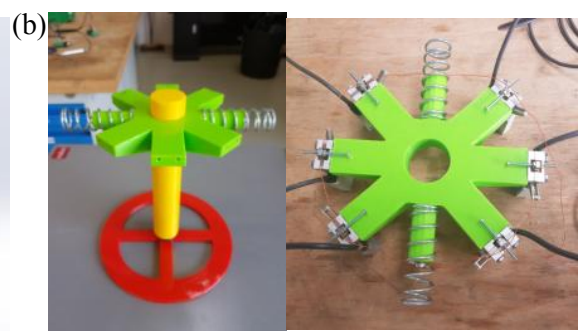

Fig. 3 Second ovalization prototype: a) SolidWorks design, b) Assembly of the 3D printed pieces constituting the prototype

Most of the two prototypes pieces designed are made of resistant plastic through the 3D printer available at the STAC (Figure 2b, Figure 3b). Both ovalization prototypes make possible the simultaneous measurement of the cavity diameter at different depths. However, the good functioning of the two prototypes is firstly tested at only one depth at a time into the cavity. 


\section{Experimental Tests and Results}

Tests were conducted in 2019 with both new ovalization prototypes under HWD impulse loading on the STAC full-scale airfield pavement test facility constructed on its site (Bonneuil-sur-Marne, France). The pavement structure (see Figure 4) is a conventional airfield pavement composed of a French standard bituminous material (NF EN 13108-1), called BBA (0/14 class 3) for the surface layer (E $=10,500 \mathrm{MPa}$ at $15^{\circ} \mathrm{C}$ and $\left.10 \mathrm{~Hz} ; \mathrm{v}=0.35\right)$, a standard bituminous material called GB $(0 / 14$ class 3$)$, for the base layer $\left(\mathrm{E}=15,600 \mathrm{MPa}\right.$ at $15{ }^{\circ} \mathrm{C}$ and $10 \mathrm{~Hz} ; \mathrm{v}=$ $0.35)$, a standard granular material, named GNT (0/31.5 type B), for the subbase layer placed upon a subgrade.

The Figure 4 illustrates also the experimental program proposed for the new ovalization system tested under HWD loads. Tests are firstly performed with the HWD plate positioned beside the cavity. The ovalization prototype is initially placed within the cavity at the pavement surface. Three HWD load levels (resp. maximum values $\mathrm{F}_{1} \sim 260 \mathrm{kN}, \mathrm{F}_{2} \sim 170 \mathrm{kN}$ and $\mathrm{F}_{3} \sim 130 \mathrm{kN}$ ) are applied, and for each load level five drops are performed for repeatability study. The acquisition frequency is chosen high enough, about $4800 \mathrm{~Hz}$, for the HWD impulse loading. Both ovalization prototypes are tested under HWD loads according to the experimental program.

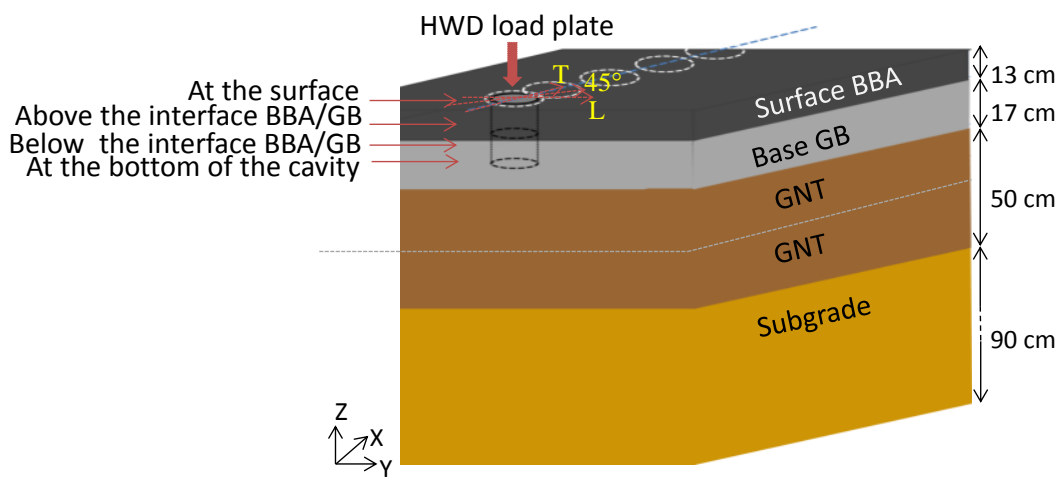

Fig. 4 STAC full scale facility and HWD and the ovalization experimental protocol (x:T and $\mathrm{y}: \mathrm{L})$

For the prototype 1, the diameter variation of the cavity is evaluated at the four depths within the bituminous layer. The implementation of this prototype is easy whatever the depth into the cavity (Figure 5a). However, an oscillation shape is observed for the diameter variation curves (Figure 5b). It can be linked to springs used in the system or to other components. Tests have been conducted with other springs, stiffer, but the oscillations were still observed. Although it makes it possible to measure easily the diameter variation in the four depths, this prototype 
needs to be thoroughly studied and improved in order to remove mechanical oscillations.

(a)

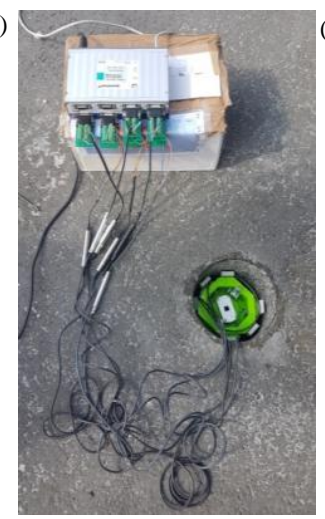

(b)

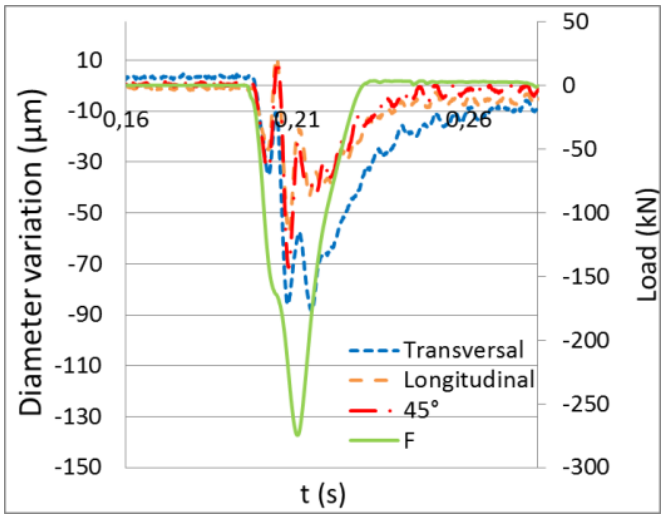

Fig. 5 a) Prototype 1 installed into the cavity, b) Diameter variations curves using prototype 1 at the surface of the cavity $\left(\mathrm{F} 1 \mathrm{max} \sim 260 \mathrm{kN} ; \mathrm{T}=36.4^{\circ} \mathrm{C}\right.$ at the bituminous layer)

The prototype 2 was tested in the same cavity than the prototype 1 , and in the same condition under HWD loads. It is easily implemented in the cavity at the surface. Tests have been carried out firstly with the central support (Figure 3). The same oscillation shape phenomena are noticed (Figure 6a). It is assumed that it is due to the use of the vertical spring. Tests are then carried out without the central support. The system remains very stable with the use of only two rigid horizontal springs. Tests are performed under the three HWD load levels and five drops for each one for repeatability study. Figure 7 histogram illustrates the average value of the cavity diameter variation in the three directions under the three load levels. The error bars highlight the repeatability of the ovalization system.
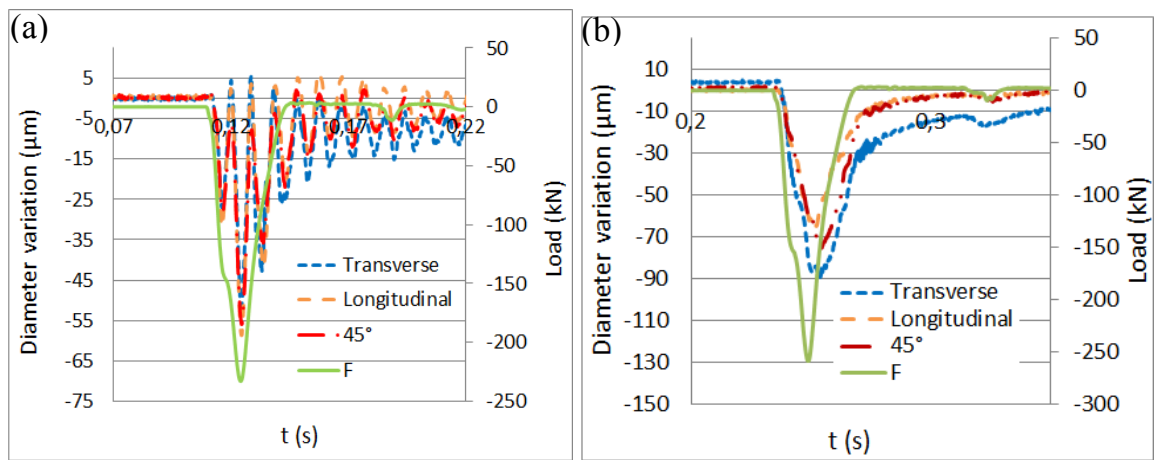

Fig. 6 Diameter variations curves using the prototype 2 at the surface of the cavity: a) with the central support $\left(\mathrm{F}_{1} \max \sim 240 \mathrm{kN}\right)$, b) Without the central support $\left(\mathrm{F}_{1} \max \sim 260 \mathrm{kN}\right)$. 


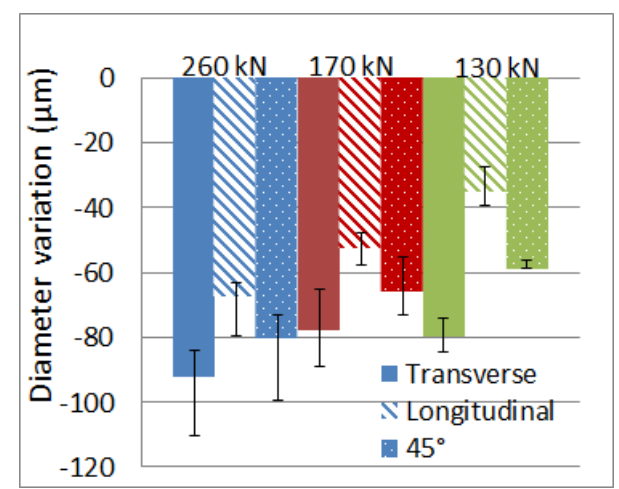

Fig. 7 Average value of the diameter variation at the pavement surface $\left(\mathrm{T}=34.5^{\circ} \mathrm{C}\right.$ at the bituminous layer; prototype 2)

The Figure $6 \mathrm{~b}$ illustrates an example of the diameter variation curves measured in the three $\mathrm{L}, \mathrm{T}, 45^{\circ}$ directions at the surface of the cavity, under HWD load applied beside the cavity using the prototype 2 without the central support. A regular shape without significant defect is noticed. Results obtained with the second prototype placed at the bottom of the bituminous course layer seem to be satisfactory. The setting up of the ovalization prototype 2 in the other depth levels of the cavity was difficult due to the stiffness of the two horizontal springs. Furthermore the adjustment of the screws attached on the tip of each sensor was a very tedious task.

Work is in progress in order to improve both prototypes and to overcome their respective limitations: mechanical vibrations reduction for the first prototype; facilitated set up for the second one.

\section{A 3D Finite Element Modelling of the Ovalization Test}

The numerical analysis is conducted using the FE software COMSOL Multiphysics. In order to limit calculation time for the 3D model, only half of the airfield pavement is modeled (thanks to the use of a symmetry plane). The specimen geometry and mesh are presented in Figure 8. It considers the real geometry of the STAC full-scale airfield pavement test facility, i.e. the layers thicknesses (Fig. 4). A mesh optimization was carried out until reaching a stabilization of the results under dynamical loading. The target numerical precision is $1 \mu \mathrm{m}$ for the diameter variation maximum value, $1 \mu \mathrm{m} / \mathrm{m}$ for peak strains and $0.1 \mathrm{MPa}$ for peak stresses. The mesh automation, using cubic and tetrahedron elements, takes into account an adjustable HWD plate position from the cavity. The mechanical behavior of the bituminous materials is supposed elastic for first simulations with an equivalent modulus norm $\mathrm{E}$ equal to $9000 \mathrm{MPa}$ and $13900 \mathrm{MPa}$ at $20^{\circ} \mathrm{C}, 30 \mathrm{~Hz}$ for BBA and GB layers respectively. 


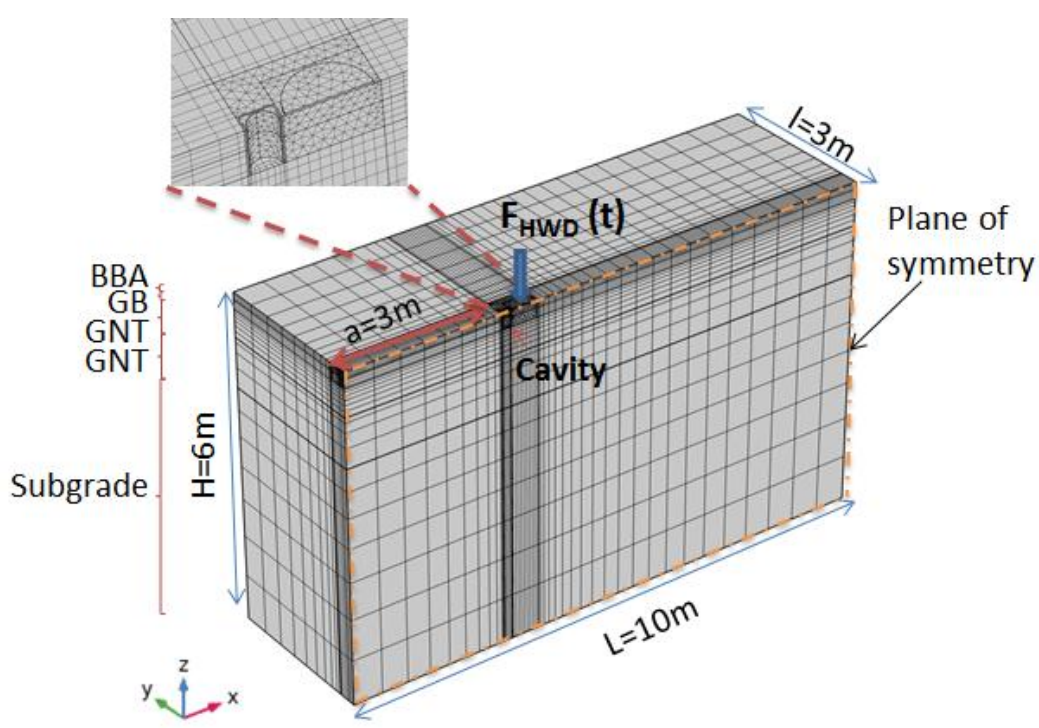

Fig. 8 Geometry and mesh of the considering airfield pavement (x:T and $y: L)$

The comparison between numerical and experimental cavity diameter variation curves in the transversal direction, obtained under $F_{1} \sim 260 \mathrm{kN}$ and $F_{2} \sim 170 \mathrm{kN}$ HWD impulse loads, are respectively presented in the Figure 9 . A good correlation of numerical and experimental diameter variation curves is observed until the maximum value for the two HWD load levels. The FEM maximum diameter variation value obtained, under both HWD load levels, is $10 \%$ higher than the experimental value one. However, the return to zero of the experimental curves is slower than the FEM one. This is probably due to the viscoelastic properties of the bituminous layers which are not taken into account in the FE modelling. These results are also observed for longitudinal and $45^{\circ}$ diameter variation curves.
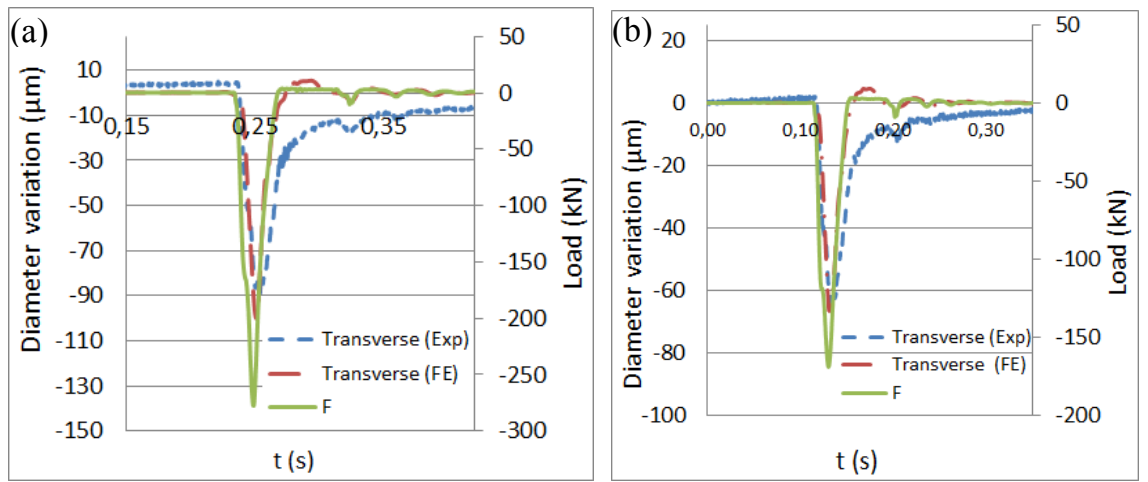

Fig. 9 FEM and experimental (Prototype2) transverse diameter variations at the surface of the cavity under HWD load: a) for $\left.\mathrm{F}_{1} \max \sim 260 \mathrm{kN}, \mathrm{b}\right) \mathrm{F}_{2} \max \sim 170 \mathrm{kN}$ 


\section{Conclusion}

To provide a reliable assessment of the interface condition in correlation to NDT, the ovalization test is an interesting complementary method. The current ovalization system developed by the CEREMA (Ruiz and Voisin 2019) was tested and some limitations were noticed (Gharbi et al. 2020). From this, the STAC is developing its own prototypes. The objectives are to adapt the ovalization system to airfield pavement and to allow the measurement of the cavity diameter variation under HWD impulse loading and different configurations:

- At different depth levels into the cavity from each part of the interface and especially at its surface,

- With the HWD plate at different position from the cavity, including the possibility to place the HWD plate centered above the cavity.

Two new ovalization prototypes are presented and first tests and results are illustrated in this present paper. The prototypes differ mainly from each other on the way the sensors are placed in contact with the different sides of the cavity.

First, it is noticed that the setting up of the two prototypes into the cavity was easily carried out. The repeatability of the ovalization measurements is checked. It is noticed from the cavity diameter variation curve obtained with the prototype 1 an oscillation shape. This may be derived from mechanical vibrations due to the use of many springs in the system. The prototype 2 made without the central support seems to be simpler than the first one and provides quite satisfactory measurements compared to those of the first prototype. A 3D finite element modelling is then proposed, involving equivalent elastic materials and fully bonded interfaces conditions. Numerical results show a good correlation with the experimental ones tested under HWD loads $\left(\mathrm{F}_{1} \sim 260 \mathrm{kN}\right.$ and $\left.\mathrm{F}_{2} \sim 170 \mathrm{kN}\right)$. The effect of the viscoelastic properties of the bituminous layers is significantly observed in the second part of the diameter variation curve, i.e. after the peak of the HWD load: the numerical (elastic) signal decreases quicker than the in-situ observations.

In the following, these first encouraging results will be pursued in order: to improve the prototypes manufactory; to take into account the viscoelasticity of the materials in the modeling (Roussel et al. 2019) and to study possible interfaces debonding condition.

\section{References}

Broutin M, Sadoun A, Duprey A (2019) Comparison between HWD Backcalculated Subgrade Dynamic Moduli and In Situ Static Bearing Capacity Tests. Airfield and Highway Pavements 2019 404-413. https://doi.org/10.1061/9780784482452.040 
Corte J, Goux M (1996) Design of pavement structures: the French technical guide. Transp Res Rep 1539:116-124

Gharbi M (2018) Caractérisation du collage des interfaces de chaussées par essais de rupture en mode I. PhD thesis, Ecole Centrale de Nantes, ED SPI N ${ }^{\circ} 602$. (http://www.theses.fr/2018ECDN0037/document)

Gharbi M, Broutin M, Boulkhemair I, Nguyen M. L., Chabot A., (2020) Analysis of Ovalization Measurements on Flexible Airfield Pavement under HWD Dynamic Impulse Load. International RILEM Symposium on Bituminous Materials (ISBM), RILEM Bookseries, Springer.

Goacolou H, Keryell P, Kobisch R, Poilane J (1983) Utilisation de l'ovalisation en auscultation des chaussées. Bulletin de Liaison des Laboratoire des Ponts et Chaussées (128): 65-75

Kobisch R, Peyronne C (1979) L'ovalisation : une nouvelle méthode de mesure des déformations élastiques des chaussées. Bulletin de Liaison des Laboratoire des Ponts et Chaussées (102): 59-71

Petit C, Chabot A, Destrée A, Raab C (2018) Interface debonding behaviour. In: Buttlar W., Chabot A., Dave E., Petit C., Tebaldi G. (Eds) Mechanisms of Cracking and Debonding in Asphalt and Composite Pavements. RILEM State-of-the-Art Reports Vol 28. Springer, Cham, pp 103-153. https://doi.org/10.1007/978-3-319-76849-6_3

Roussel JM, Sauzéat C, Di Benedetto H, Broutin M (2019) Numerical simulation of falling/heavy weight deflectometer test considering linear viscoelastic behaviour in bituminous layers and inertia effects. Road Material and Pavement Design 20 (sup1): S64-S78. https://doi.org/10.1080/14680629.2019.1587491

Ruiz O, Voisin G (2019) L'essai d'ovalisation. RGRA (962). https://www.editionsrgra.com/revue/962/auscultation/lessai-dovalisation (accessed November 3, 2019).

Sadoun A, Broutin M, Simonin J-M (2016) Assessment of HWD Ability to Detect Debonding of Pavement Layer Interfaces. In: Chabot A, Buttlar WG, Dave EV, et al. (eds) 8th RILEM International Conference on Mechanisms of Cracking and Debonding in Pavements. Springer Netherlands, Dordrecht, p 763-769 